\title{
Complement and the damaging effects of cardiopulmonary bypass*
}

\begin{abstract}
"One of the most serious difficulties encountered in total body perfusion is the profound effect upon the lungs that may occur in certain patients. It is indeed discouraging to perform open cardiac corrective surgery, to have the patient remain in excellent condition throughout the procedure and for a day or two thereafter, finally succumbing to pulmonary insufficiency while the heart itself remains strong to the very end." F D DODRILl, Chicago, September 1957
\end{abstract}

This statement opened the session on "postperfusion pulmonary dysfunction" at one of the first major international meetings devoted to the subject of cardiopulmonary bypass. Now, after 25 years of research and development in oxygenation and extracorporeal circulation, it is still apparent that adverse effects occur in every patient and continue to limit the scope of cardiac surgery as it could be practised today. In adult practice the full-blown clinical syndrome of haemorrhagic pulmonary oedema, fever, haemolysis, renal dysfunction, and abnormal bleeding is rarely seen. The typical patient leaves the intensive care unit after 12-24 hours and is ready for home in little more than a week. In the first three months of life, however, there is a considerable difference in the results of cardiac surgery between patients who do and do not require cardiopulmonary bypass. ${ }^{1}$ Thus it is still safer to construct a shunt in a small infant with tetralogy of Fallot than to perform complete correction. ${ }^{2}$ There is no surgical reason for this and similar numbers of infants are ill in the two groups, but many deaths after total correction are attributable not to cardiac failure but to pulmonary problems, bleeding disorders, and other complications, which make us believe that the limitation to successful surgery is the "dose" of cardiopulmonary bypass. In fact, in the mid-1950s Lillehei and colleagues at the University of Minnesota

\footnotetext{
*This editorial is based on an essay which was awarded the Peter Allen Prize for 1982 by the Society of Thoracic and Cardiovascular Surgeons of Great Britain and Ireland.
}

Address for reprint requests: Mr Stephen Westaby, Harefield Hospital, Uxbridge, Middx UB9 6JH. used cross-circulation between parent and child for the repair of intracardiac defects, ${ }^{3}$ achieving results that were not equalled for 20 years with cardiopulmonary bypass.

"Postperfusion lung" is characterised clinically by increased work of breathing, arterial hypoxaemia with an increased alveolar-arterial oxygen difference, and increased fluid in the tracheobronchial tree. Several workers have shown consistent pathological changes in ultrastructure in lung biopsy specimens taken from surviving patients one to four hours after bypass. ${ }^{4-6}$ Interstitial oedema is always present and at times types I and II pneumocytes show necrosis and sloughing. The capillaries appear congested with focal endothelial damage consisting of swelling of the cells and their mitochondria and there are collections of leucocytes with their degranulation products in apposition to the capillary membranes. There is evidence that the infant lung may be more susceptible to pulmonary damage. Firstly, infants' alveolar capillary membrane has a greater tendency to leak fluid $;^{78}$ and, secondly, the lungs are smaller and the pressures in the pulmonary artery may be viewed as hydrostatic columns of water, so that left atrial or pulmonary arterial pressures of equal magnitude in adults and children will have a much greater effect on the smaller lungs of children. ${ }^{9}$ Other workers have claimed that pulmonary damage may result from hypothermia or ischaemia during bypass, though Barratt-Boyes and colleagues state that the use of profound hypothermia and total circulatory arrest has diminished the incidence of postoperative pulmonary complications. ${ }^{10}$ This implies that a shorter period of bypass gives a smaller dose of whatever is the cause of the problem-a hypothesis for which I hope later to give supporting evidence.

\section{Role of the oxygenator system}

It is well recognised that the most important intraoperative factor to influence the lungs after bypass is the oxygenator system and a considerable amount of experimental work confirms this. Lee and others ${ }^{11}$ showed denaturation of plasma proteins with release of abnormal proteins, chylomicrons, and free fat globules and suggested that this occurred by molecu- 
lar distortion at the gas-liquid interface of the bubble oxygenator. Microaggregates have been found in the pulmonary vasculature after bypass and it has been assumed that these may occlude capillaries and damage the capillary endothelium. ${ }^{612}$ Membrane oxygenators and improved filters, however, have not contributed greatly to eradicating the problem. Hollenburg et al showed that infusion of plasma taken from patients during bypass into experimental animals often proves lethal and that merely recirculating blood through a bubble oxygenator produced highly vasoactive material..$^{13}$ Pacifico and others, using indicator dilution techniques to determine compartmental water before and after cardiac surgery, showed a $7 \%$ increase in extracellular water and a $12 \%$ increase in interstitial water 48 hours after operation. ${ }^{14}$ In the lung this reduces compliance, thus increasing the work of breathing, which in infants and debilitated adults may lead to prolonged intubation and increased risk of infection and death from pulmonary causes.

Parker $e a l^{15}$ found a significant decrease in serum complement after bypass, which fitted well with the findings of others that the postoperative immune response to bacteria is altered; but at that time it was impossible to determine whether complement consumption was due to denaturation or to triggering of the complement cascade. ${ }^{16}$ If the latter, then does bypass initiate the release of powerful anaphylatoxins? This important question remained unanswered for many years while further investigations concentrated on the prevention of shear stress, which damages the blood's cellular components, and the elimination of abnormal substances, such as macro or micro air bubbles, fat, fibrin, and tissue thromboplastins, which have been blamed for the pulmonary, cerebral, and renal problems after prolonged perfusion. Many practical improvements were made empirically and some on theoretical grounds. Haemodilution, hypothermia, and elimination of extraneous blood contributed greatly to the safety of bypass; whereas innovations such as pulsatile flow, membrane oxygenation, improved filters, and defoaming agents have achieved little despite their initial promise. Apparently a fundamental problem remains and minimises their potentially beneficial effects.

We should therefore reconsider the effects of exposure of blood to the allegedly biocompatible but unphysiological materials of the bypass circuit. These effects are related both to the nature and to the area of such surfaces and are of special interest since those that suffer most are infants, who because of their smaller blood volume in relation to the surface area of oxygenator components must receive relatively greater exposure to these surfaces than do their adult counterparts. When blood first contacts the venous cannulas Hageman factor (XII) is activated to initiate the clotting cascade and without heparin bypass could not continue. The humoral cascades are closely interlinked, however, and Hageman factor also activates the kinin-bradykinin system, which in turn triggers the fibrinolytic system and the alternative complement pathway. Thus it is highly probable that during bypass the components of these systems are consumed by activation, not denaturation. The complement cascade is an important part of our host defence mechanism and it would be naive to expect the body to tolerate exposure of its total blood volume to the foreign materials in the bypass circuit without some sort of defence response.

\section{The inflammatory response}

In 1981 Kirklin Stewart and Blackstone at the University of Alabama noted that those cellular and humoral reactions that are known to be activated by contact of blood with foreign materials take part in the acute inflammatory response at the site of local injury. Local inflammation begins with platelet adherence and activation of the coagulation cascade to form a haemostatic plug. Chemotactic agents, including complement-derived anaphylatoxins, are liberated to attract leucocytes and monocytes and tissue oedema and fever follow. Might therefore the adverse effects of cardiopulmonary bypass, which limit the benefits of membrane oxygenation and pulsatile flow, result from a whole-body inflammatory response to the materials of the bypass circuit? If so, we should expect coagulation disorders and sequestration of complement-activated white cells in the lungs and kidneys, giving rise to interstitial oedema, fever, and eventual organ dysfunction. Notably, fever of non-infective origin that is influenced by anti-inflammatory agents, such as indomethacin, is an invariable feature of the immediate period after bypass surgery. ${ }^{17}$

In 1977 Craddock and coworkers proposed a mechanism for pulmonary dysfunction in patients undergoing haemodialysis and leucapheresis. ${ }^{18}$ They found that during dialysis there was a selective loss of neutrophils and monocytes from the systemic circulation with trapping in the lungs. Both of these cells have membrane binding sites for the comple- 0 ment anaphylatoxin C5a. In a study of animal mod- $\mathbb{D}$ els for the shock lung syndrome, Hohn et al gave ? plasma incubated with zymosan to rabbits (zymosan $T$ activates complement); this resulted in profound systemic neutropenia followed by hypoxaemia, tachypnoea, and haemorrhagic pulmonary $\stackrel{\mathbb{Q}}{\varrho}$ oedema. ${ }^{19}$ Electron microscopy showed neutrophils $\frac{\sigma}{\sigma}$ 
marginated in the pulmonary capillaries; these, it is suggested, release their lysosomal granule contents (including proteases and cathepsins) and free radicals, which damage the capillary membrane and cause cell death. ${ }^{20}$ Undoubtedly this picture is similar to that shown by electron microscopy of the lung tissue after cardiopulmonary bypass. The question therefore arises of whether cardiopulmonary bypass releases complement-derived anaphylatoxins and, if so, what initiates this response.

In 1981 Hammerschmidt and co-workers claimed that the systemic neutropenia with pulmonary sequestration of neutrophils and monocytes that occurs in patients during bypass is direct evidence of complement activation. ${ }^{21}$ Their data for total complement levels and C3 and C5 fragments, however, did not support their hypothesis or clarify the relation between complement activation and peripheral leucopenia. Cooper had previously shown that infusion of activated complement into sheep produced a rise in serum concentrations of prostaglandin metabolites (thromboxane $\mathrm{B}_{2}$ ) and that treatment with prostaglandin inhibitors (indomethacin or sulphinpyrazone) eliminated both the prostaglandin rise and pulmonary dysfunction without altering the peripheral leucopenia. ${ }^{22}$ Thus a positive link between complement, white cells, cardiopulmonary bypass, and pulmonary dysfunction remained in doubt, pending direct evidence of complement activation with anaphylatoxin release.

At this time the cellular immunology group at the Scripps Institute at La Jolla, California, was investigating the $\mathrm{C} 3$ and $\mathrm{C} 5$ components of the complement cascade and their cleavage products $\mathrm{C} 3 \mathrm{a}$ and C5a. These fragments are potent anaphylatoxins whose physiological activity includes increased capillary permeability, smooth muscle contraction, histamine release from mast cells, and polymorphonuclear chemotaxis with enzyme release. ${ }^{23}$ Both are liberated by the classical and alternative pathways of complement activation, as are $\mathrm{C} 8$ and $\mathrm{C} 9$, which have been implicated in membrane damage and the renal changes of experimental and hypocomplement aemic glomerulonephritis. Hugli and Chenoweth succeeded in isolating C3a and C5a, determined their amino-acid sequence, and synthesised their molecules, thus establishing a method for immunoassay. ${ }^{24}$ Though both are stable, C5a is rapidly bound to neutrophil and monocyte cell membranes, so that meaningful assay in the presence of these cells is impossible. ${ }^{25} \mathrm{C} 3 \mathrm{a}$ is less rapidly bound to tissue and provides a good marker of complement activation by either pathway. Demonstration of $\mathrm{C3a}$ in the serum of bypass patients would therefore provide direct evidence of complement activation and give support to the hypothesis that the damaging effects of cardiopulmonary bypass are the result of an inflammatory response to the materials of the bypass circuit.

\section{Clinical studies}

Chenoweth worked in conjunction with the University of Alabama and in adult patients undergoing coronary artery surgery with complete haemodilution showed that $\mathrm{C} 3 \mathrm{a}$ appeared rapidly in the serum at the onset of bypass and accumulated in increasing quantity until the end of perfusion, when levels fell rapidly owing to tissue binding. ${ }^{26}$ As suspected, there was no significant rise in C5a, but differential white cell counts from the right and left atria before perfusion and after re-establishment of pulmonary blood flow at partial bypass showed trapping of neutrophils and monocytes in the pulmonary vascular bed. Lymphocytes and eosinophils, which do not have binding sites for $\mathrm{C} 5 \mathrm{a}$, were unaffected. Estimation of $\mathrm{C} 4$ levels showed these to be unchanged, so complement activation evidently occurred by the alternative (or properdin) pathway. Whether the pulmonary sequelae of cardiopulmonary bypass, which range from modest interstitial oedema to haemorrhagic pulmonary oedema, can be related to white cell sequestration remains speculative, though the change in mobility of white cells with margination against the capillary membrane in response to $\mathrm{C5a}$ binding is known to be associated with degranulation and release of lysosomal enzymes.

An understanding of this complex series of events is of practical importance only if we can establish a direct link with abnormal postoperative events and formulate methods of treatment. With colleagues at the University of Alabama I set out to determine which components of the bypass circuit trigger the complement cascade and what other factors might influence anaphylatoxin release during perfusion. Dialysis workers had implicated nylon, which with polyurethane, polyethylene, polyvinyl chloride and polycarbonate form an important part of most bubble oxygenators and cardiotomy reservoirs. Samples of these and other materials taken from membrane oxygenators, bypass tubing, line filters, and cannulas were incubated with whole blood and serum to test their ability to activate complement in vitro. We found that all materials except polycarbonate activate complement to some extent. Nylon is particularly potent, though silicone and other materials from membrane oxygenators also have this activity. It is therefore unrealistic to expect a change of materials in the components of the bypass circuit to change the overall quantity of anaphylatoxin released. The influence of temperature on the kinetics of complement activation were studied both in 
vitro and vivo and, inevitably, less anaphylatoxin release occurs at lower temperatures. Anecdotal clinical evidence that this is the case comes from Ebert, who for different reasons precools his bypass circuit and oxygenator to $10^{\circ} \mathrm{C}$ before starting perfusion in infants and small children and who quotes a very low incidence of pulmonary dysfunction after perfusion.

Interestingly, complement activation during cardiac surgery does not cease with the termination of bypass. For many years it has been apparent that neutralisation of heparin with protamine may result in profound haemodynamic collapse in certain patients, often those who are critically ill and can least tolerate further instability. ${ }^{27} 28$ Jastrebski and colleagues studied the haemodynamic response after heparin neutralisation with protamine in dogs. ${ }^{29}$ This is characterised by an acute rise in pulmonary vascular resistance and pulmonary arterial pressure, with peripheral vasodilation and pooling of blood in the splanchnic bed. Several poorly substantiated explanations have been offered in published reports, usually implicating hypersensitivity to protamine itself. Certain animals such as dogs and rabbits have very reactive mast cells and platelets and may release large quantities of histamine and serotonin in response to $\mathrm{C} 3 \mathrm{a}$ or $\mathrm{C5}$ binding, with results that are not easily reproducible in man. Nevertheless, since reactions between anions and cations are known to activate the classical complement pathway, ${ }^{30}$ we wondered whether the adverse reactions after neutralisation of heparin with protamine in man might also be related to this process. We therefore studied $\mathrm{C} 3 \mathrm{a}$ levels before and after protamine administration and found release of the anaphylatoxin shortly after beginning protamine infusion. Estimation of total C4 from the same samples showed that this was used up in the process, which, unlike activation by foreign materials, must therefore occur by the classical pathway.

\section{Conclusion}

It is too soon to claim that the postperfusion syndrome is the direct consequence of a systemic inflammatory response caused by exposure of blood to unphysiological surfaces, though this is an attractive hypothesis. We have investigated one potent mediator of the inflammatory response, found it to be liberated by certain materials in the bypass circuit, and confirmed its presence in the serum of patients during cardiopulmonary bypass. Its appearance can be correlated with white cell sequestration in the lungs.

In an attempt to establish or refute a link between complement-derived anaphylatoxin and an abnor- mal postoperative course, we have recently carried out an extensive and detailed clinical study to relate C3a levels to clinical events, including pulmonary, renal, cerebral, and clotting disorders after cardiopulmonary bypass. Several patients suffered an obvious postperfusion syndrome during the course of this study so the results should prove interesting.

Potentially there are many simple therapeutic ways of intervening in the pathological sequence described. An initial response by manufacturers was to search for substitute materials for oxygenator components but this is probably of limited value since, whatever the alternative material, the body's defence mechanisms will respond by means of platelet adherence, protein denaturation, or activation of the plasmin or the kallikrein or bradykinin system if not through complement activation. The body has a natural response to every insult and the best we can hope to achieve is to minimise the effects. We have been slow to understand this in extracorporeal technology but may now be on the verge of unravelling the damaging effects of cardiopulmonary bypass, which have contributed considerably to the morbidity and mortality of cardiac surgery over the past 30 years.

Cardiothoracic Surgical Unit Harefield Hospital Uxbridge, Middlesex

\section{References}

${ }^{1}$ Kirklin JK, Blackstone EH, Kirklin JW, et al. Intracardiac surgery in infants under 3 months. Incremental risk factors for hospital mortality. Am J Cardiol 1981;48:500-6.

${ }^{2}$ Kirklin JW, Blackstone EH, Pacifico AD, et al. Routine primary repair vs two stage repair of tetralogy of Fallot. Circulation 1979;60:373-86.

${ }^{3}$ Lillehei CW, Cohen M, Warden HE, et al. The results of direct vision closure of ventricular septal defects in eight patients by means of controlled cross circulation. Surg Gynecol Obstet 1955;101:447-66.

${ }^{4}$ Connell RS, Page US, Barley TD, et al. The effect on pulmonary ultrastructure of Dacron-wool filtration during cardiopulmonary bypass. Ann Thorac Surg 1973;15:217-29.

5 Asada S, Yamaguchi M. Fine structural changes in the lung following cardiopulmonary bypass. Chest 1971;59:478-83.

${ }^{6}$ Ratliff NB, Young WG, Hackel DB, et al. Pulmonary injury secondary to extracorporeal circulation. $J$ Thoracic Cardiovasc Surg 1973;65:425-32.

${ }^{7}$ Levine OR, Rodriguez-Martinez F, Mellirs RB. Fluid filtration in the lung of the intact puppy. $J$ Appl Physiol 1973;34:683-6.

${ }^{8}$ Gomes MMR, Feldt RH, McGoon DC, Danielson GK. Total anomalous pulmonary venous connection. Surgical considerations and results of operation. $J$ Thorac Cardiovasc Surg 1970;60:116-22. 
9 Iliff LD, Greene RE, Hughes JH. Effect of interstitial oedema on distribution of ventilation and perfusion in isolated lung. J Appl Physiol 1972;33:462-7.

${ }^{10}$ Barrat-Boyes BG, Simpson M, Neutz JM. Intracardiac surgery in neonates and infants using deep hypothermia with surface cooling and limited cardiopulmonary bypass. Circulation 1971;43 and 44:suppl 2:25-30.

${ }^{11}$ Lee WH, Krumbhoar D, Fonkalsrad EW, Schjeide OA, Maloney JV. Denaturation of plasma proteins as a cause of morbidity and death after intracardiac operations. Surgery 1961;50:29-39.

${ }^{12}$ Connell RS, Swark RL. Pulmonary microembolism after blood transfusion: an electron microscopic study. Ann Surg 1973;177:40-50.

${ }^{13}$ Hollenburg R, Pruett R., Thal A. Vasoactive substances liberated by prolonged bubble oxygenation. $J$ Thorac Cardiovasc Surg 1963;45:402-11.

${ }^{14}$ Pacifico AD, Digerness S, Kirklin JW. Acute alterations of body composition after open intracardiac operations. Circulation 1970;41:331-41.

is Parker DJ, Cantrell JW, Karp RB, et al. Changes in serum complement and immunoglobulins following cardiopulmonary bypass. Surgery 1972;71:824-7.

${ }^{16}$ Hairston P, Manos JP, Graber CD, et al. Depression of immunologic surveillance by pump oxygenation perfusion. Surg Res 1969;9:587-93.

${ }^{17}$ Livelli FD, Johnson RA, McEnany MT, et al. Unexplained in-hospital fever following cardiac surgery. Circulation 1978;57:968-75.

${ }^{18}$ Craddock PR, Fehr J, Dalonasco AP, et al. Pulmonary vascular leukostasis resulting from complement activation by dialyser cellophane membranes. J Clin Invest 1977;59:879-88.

${ }^{19}$ Hohn DC, Mayers AJ, Ghersini ST, et al. Production of pulmonary injury by leukocytes and activated complement. Surgery 1980;88:48-58.

${ }^{20}$ Replogle RL, Gazzaniga AB, Groos RE. Use of corticosteroids during cardiopulmonary bypass. Possible lysosome stabilisation. Circulation 1966;33:suppl 1:86-92.

${ }^{21}$ Hammerschmidt DE, Strancek DF, Bowers TK, et al.
Complement activation and neutropenia occurring during cardiopulmonary bypass. J Thorac Cardiovasc Surg 1981;81:370-7.

${ }^{22}$ Cooper JD, McDonald JWD, Ali M, et al. Prostaglandin production associated with the pulmonary vascular response to complement activation. Surgery 1980;88:215-21.

${ }^{23}$ Hugli TE. Complement anaphylatoxins as plasma mediators, spasmogens and chemotoxins. In: Bing DH, ed. The chemistry and physiology of human plasma proteins. New York: Pergamon Press, 1979:225-80.

${ }^{24}$ Hugli TE, Chenoweth DE. Biologically active peptides of complement: techniques and significance of $\mathrm{C} 3 \mathrm{a}$ and C5a measurements. In: Nakamura RM, Dito WR, Tucker ES, eds. Immunoassays: clinical laboratory techniques for the 1980s. New York: Alan R Liss, 1980:443-460.

${ }^{25}$ Chenoweth DE, Hugli TE. Binding internalisation and degradation of $\mathrm{C} 5 \mathrm{a}$ by neutrophils. Fed Proc 1980;39:1049.

${ }^{26}$ Chenoweth DE, Cooper SW, Hugli TE, et al. Complement activation during cardiopulmonary bypass: evidence for generation of $\mathrm{C} 3 \mathrm{a}$ and $\mathrm{C} 5 \mathrm{a}$ anaphylatoxins. $N$ Engl J Med 1981;304:497-503.

${ }^{27}$ Olinger GN, Becker RM, Bonchek LI. Non-cardiogenic pulmonary oedema and peripheral vascular collapse following cardiopulmonary bypass: rare protamine reaction? Ann Thorac Surg 1980;29:20-5.

${ }^{28}$ Lakin JD, Blocker TJ, Strong DM, et al. Anaphylaxis to protamine sulphate mediated by a complement dependent IgG antibody. J Allergy Clin Immunol 1978;61:102-7.

29 Jastrebski J, Sykes MK, Woods DG. Cardiorespiratory effects of protamine after cardiopulmonary bypass in man. Thorax 1974;29:534-8.

${ }^{30}$ Pont R, Ertel N, Eisenstein R, et al. Complement activation in interaction of polyanions and polycations. $I$. Heparin-protamine induced consumption of complement. J Immunol 1975;114:120-5. 